\title{
ON A LOCAL SOLVABILITY OF THE MULTIDIMENSIONAL MUSKAT PROBLEM WITH A FRACTIONAL DERIVATIVE IN TIME ON THE BOUNDARY CONDITION
}

\author{
NATALiYA VASYLYEVA
}

Abstract. In this paper, we analyze anomalous diffusion version of the multidimensional Muskat problem without surface tension on a free boundary. We prove the existence and uniqueness of the classical solution to this moving boundary problem locally in time.

Mathematics subject classification (2010): Primary 35R35, 35C15; Secondary 35R11, 35B65. Keywords and phrases: Free boundary problem, Muskat problem, anomalous diffusion, Caputo derivative.

\section{REFERENCES}

[1] D. Ambrose, Well-posedness of two-phase Hele-Shaw flow without surface tension, European J. Appl. Math. 15 (2004) 597-607.

[2] C. ATKINSON, Moving boundary problems for time fractional and composition dependent diffusion, Frac. Calcul. and Appl. Analysis 15, n. 2 (2012) 207-221.

[3] B. V. BAZALIY, On a proof of the classical solvability of the Hele-Shaw problem with a free boundary, Ukr. Math. J. 50 (1998) 1452-1462.

[4] B. V. BaZaliy, N. Vas YlyeVa, The two-phase Hele-Shaw problem with a nonregular initial interface and without surface tension, J. Math. Phys. Anal. Geom. 10, n. 1 (2014) 3-43.

[5] B. V. BAZALIY, N. VASYLYEVA, The Muskat problem with surface tension and a nonregular initial interface, Nonlinear Analysis: Theory, Meth. and Appl. 74 (2011) 6074-6096.

[6] J.-P. Bouchaud, A. Georges, Anomalous diffusion in disordered media: statistical mechanisms, models and physical applications, Phys. Rep. 195 (1990) 127-293.

[7] A. ERDÉLYI, Higher transcendental functions v. 3, Mc Graw-Hill, New York, 1955.

[8] J. Escher, B. V. MATIOC, On the parabolicity of the Muskat problem: well-posedness, fingering and stability results, Z. Anal. Anwend. 30 no. 2, (2011) 193-218.

[9] E. I. HanZawa, Classical solution of the Stefan problem, Tohoku Math. J. 33 (1981) 297-335.

[10] S. Howison, A note on the two-phase Hele-Shaw problem, J. Fluid Mech. 409 (2000) 243-249.

[11] L. JiAng, Y. CHEN, Weak formulation of a multidimensional Muskat problem, Free boundary problems: theory and applications, vol. II (Irsee, 1987), (1990) 509-513. Pitman Research Notes in Mathematics Seris, 186. Longman, Harlow.

[12] A. A. Kilbas, H. M. SRivastava, J. J. Trujillo, Theory and applications of fractional differential equations, North-Holland Mathematics Studies, 204, Elsevier Science B.V., Amsterdam, 2006.

[13] A. N. Kochubei, Fractional-parabolic systems, Potential Analysis 37, 1 (2012) 1-30.

[14] M. KRASNOSCHOK, N. VASYLYeVA, On nonclassical fractional boundary-value problem for the Laplace operator, J. Diff. Equ., 257, n. 6 (2014) 1814-1839.

[15] O. A. Ladyzhenskaia, V. A. Solonnikov, N. N. Ural'tseva, Linear and quasilinear parabolic equations, Academic Press, New York, 1968.

[16] O. A. Ladyzhenskaia, N. N. URAL'TSEVA, Linear and quasilinear elliptic equations, Academic Press, New York, 1968.

[17] B.-T. LIU, J.-P. HsU, Theoretical analysis on diffusional release from ellipsoidal drug delivery devices, Chemic. Engin. Scien. 61 (2006) 1748-1752. 
[18] J. LIU, M. XU, An exact solution to the moving boundary problem with fractional anomalous diffusion in drug release devices, Z. Angew. Math. Mech. 84, n. 1 (2004) 22-28.

[19] J. LIU, M. XU, Some exact solutions to Stefan problems with fractional differential equations, J. Math. Anal. Appl. 351, (2009) 536-542.

[20] A. LUNARDI, Analytic semigroups and optimal regularity in parabolic problems, Progress in Nonlinear Differential Equations and their Applications 16, Basel: Birkhäuser Verlag, 1995.

[21] F. MAINARDI, Fractional calculus: some basic problems in continuum and statistical mechanics, in: A. Garpinteri, F. Mainardi (Eds.), Fractals and fractional calculus in continuum mechanics, SpringerVerlag, New York, (1997) 291-348.

[22] R. Metzler, J. Klafter, Boundary value problems for fractional diffusion equations, Physica A 278 (2000) 107-125.

[23] M. MUSKat, Two fluid systems in porous media. The encroachment of water into an oil sand, Physics 5 (1934) 250-264.

[24] J. A. Ochoa-Tapia, F. J. Valdes-Parada, J. Alvarez-Ramirez, A fractional-order Darcy's law, J. Physica A 374 (2007), 1-14.

[25] F. OTTо, Viscous fingering: an optimal bound on the growth rate of the mixing zone, SIAM J. Appl. Math. 57 no. 4 (1997) 982-990.

[26] A. V. Psknu, Partial differential equations of the fractional order, Nauka, Moscow, 2005 (in Russian).

[27] A. V. PSKHU, The fundamental solution of a diffusion-wave equation of fractional order, Izvestia RAN 73 (2009) 141-182 (in Russian).

[28] JA. A. Roitberg, Z. G. Sheftel', General boundary value problems for elliptic equations with discontinuous coefficients, Soviet. Math. Dokl. 4 (1963) 231-234 (in Russian).

[29] S. G. Samko, A. A. Kilbas, O. I. Marichev, Fractional integrals and derivatives, Gordon and Breach Science Publishers, Philadelphia, 1993.

[30] M. Siegel, R. CAFLISCH, S. Howison, Global existence, singular solutions, and ill-posedness for the Muskat problem, Comm. Pure and Appl. Math. 57 (2004) 1374-1411.

[31] V. A. SOLONNIKOV, Estimates for the solution of the second initial-boundary value problem for the Stokes system in spaces of functions with Hölder-continuous derivatives with respect to the space variables, J. Math. Sci. 109, 5, (2002) 1997-2017.

[32] N. VASYlyeVa, L. VynNytska, On a multidimensional moving boundary problem governed by anomalous diffusion: analytical and numerical study, Nonlinear Differ. Equ. Appl. DOI 10.1007/s00030-014-0295-9, 2014.

[33] V. R. VOLLER, An exact solution of a limit case Stefan problem governed by a fractional diffusion equation, Internat. J. Heat and Mass Transf. 53 (2010) 5622-5625.

[34] C. J. VogL, M. J. Miksis, S. H. Davis, Moving boundary problem governed by anomalous diffusion, Proc. R. Soc. A 468 (2012) 3348-3369.

[35] V. R. Voller, F. Falcini, R. Garra, Fractional Stefan problems exibiting lumped and distributed latent-heat memory effects, Phys. Rew. E 87 (2013) 042401.

[36] F. YI, Local classical solution of Muskat free boundary problem, J. Partial Diff. Eqs. 9 (1996) 84-96. 